\title{
Desafios e possibilidades educomunicativas na produção editorial e na mediação de livros-aplicativos
}

Samira Almeida Pinto

Jornalista, editora e especialista em Educomunicação pela ECA-USP.

E-mail: samira@storymax.me

Maria Cristina Castilho Costa

Doutora em Ciências Sociais pela FFLCH-USP, livre-docente em Ciências da Comunicação pela ECA-USP, professora associada 3 da ECA-USP, coordenadora do Observatório de Comunicação, Liberdade de Expressão e Censura da USP.

E-mail: criscast@usp.br

Resumo: Este artigo descreve desafios e oportunidades experimentados por profissionais da cadeia de produção e difusão do livro infantojuvenil diante da emergência de inovações no suporte de leitura (agora eletrônico) e na linguagem (agora hipermídia). O objetivo dessa sistematização executada como monografia apresentada para obtenção do título de especialista em Educomunicação em 2015 — é possibilitar que a comunicação entre criadores, publicadores, pesquisadores e mediadores seja gerida de forma a garantir a riqueza de conteúdos e, ao mesmo tempo, sua clareza e harmonia: essencial para engajar leitores e promover experiências novas e profundas com a leitura, considerando seu impacto na criação da linguagem e na visão de mundo do indivíduo.

Palavras-chave: livro-aplicativo; educomunicação; narrativas; produção editorial; mediação de leitura.
Abstract: This paper describes challenges and opportunities experienced by professionals in the production chain and dissemination of children's book on the emergence of innovations in reading support (now electronic) and language (now hypermedia). The purpose of this systematization - performed as a monograph presented to obtain the title of specialist in Educommunication in 2015 - is to enable the communication between creators, publishers, researchers and mediators to be managed to ensure the wealth of content and at the same time, his clarity and harmony: essential to engage readers and promote new and profound experiences with reading, considering its impact on the creation of language and the individual worldview.

Keywords: book app; educommunication; narratives; editorial production; reading mediation. 
comunicação \& educação • Ano XXI • número 1 • jan/jun 2016

\section{INTRODUÇÃO: NARRATIVAS CONSTROEM NOSSA CULTURA}

Para conhecer o humano universal, lidar com a temporalidade da vida, acessar a cultura e a tradição do grupo de que fazemos parte, interpretar nossa realidade ou traçar sonhos e destinos, a narrativa sempre foi o principal instrumento de transmissão do conhecimento e dos mitos da humanidade.

Nascidas nas mais recônditas realidades antigas e trazidas a nós por meio da "lenta ruminação das consciências camponesas"1, as histórias que ouvimos, contamos, escrevemos e interpretamos nas mais diversas linguagens "dão sentido à qualquer existência"² e "são formas de estabelecer modulações e durações, arquitetando a temporalidade humana".

Datam da Antiguidade aqueles que foram considerados os primeiros registros escritos das narrativas populares, mas foi na Idade Média, com o surgimento do códex, que vivemos a primeira grande revolução nesse campo: a sua encadernação dobrada e costurada oferecia muito mais praticidade de leitura e portabilidade.

Essa revolução fica completa, no entanto, apenas no século XV, quando Gutenberg apresenta os tipos móveis e torna possível a reprodução rápida e com qualidade de páginas impressas.

A indústria do livro transformava-se definitivamente ali - muitos afirmam que ela nasce naquele momento, pois foi aquela invenção que permitiu industrializar a impressão no ocidente - e isso trouxe uma série de impactos, conforme ainda hoje se pode observar. O processo de impressão (e principalmente seu suporte) foi recebendo evoluções e melhorias com o passar do tempo, mas seu cerne preserva-se até os dias de hoje.

1. CALVINO, Ítalo. Fábulas italianas. São Paulo: Companhia das Letras, 1993 , p. 14-15.

2. ECO, Umberto. Seis passeios pelos bosques da ficção. São Paulo: Companhia das Letras, 1994, p. 145.

3. COSTA, Maria Cristina Castilho. A milésima segunda noite: Da narrativa mítica à telenovela - Análise estética e sociológica. São Paulo: Annablume/Fapesp, 2000 , p. 41.

\section{LEITURA E LEITURAS: DO ANALÓGICO AO ELETRÔNICO-DIGITAL}

É marcadamente a partir dos anos 1960 que os computadores passam a fazer parte do universo da leitura. Do Projeto Xanadu - criado por Ted Nelson, em Harvard, para dar origem a uma biblioteca em que os conteúdos se entrecruzavam — até o nascimento da World Wide Web (1990), a partir de estudos de Tim Bernes-Lee, passaram-se apenas trinta anos.

Em 1996 aparecem os primeiros leitores eletrônicos para livros digitais e, em 2010, foi lançado o tablet como o conhecemos hoje, o iPad - que reunia em um só aparelho todas as possibilidades de uso da linguagem e de interatividade para a transmissão de narrativas hipermidiáticas.

Impulsionados pela evolução da tecnologia eletrônica, nas últimas décadas temos vivido um processo semelhante ao experimentado após a invenção da prensa de tipos móveis: a revolução eletrônica-digital-hipermídia tem sacodido o mundo da produção e do consumo de todo tipo de conteúdo, incluindo o literário. 
Trata-se de uma evolução que, em termos de construção e difusão de discursos, se dá especialmente por meio da adição de novas linguagens, de sua organização e da fusão delas num só componente significativo.

Se tratamos o advento das novas tecnologias (e, consequentemente, novas mídias e linguagens) como ondas, iniciando pelo livro - um objeto portátil com texto impresso numa ordem linear e progressiva - logo o contrastamos com o hipertexto, que, ao tirar o texto do papel, oferece uma disposição completamente fluida, adaptável, para qualquer narrativa: conforme o desejo do leitor, não linear, nem progressiva.

A onda seguinte é a do multimídia, quando mais de uma linguagem (texto, imagem e som) pode ser usada para compor o mesmo discurso, evoluindo para a hipermídia, conforme explica Petry4:

Tendo surgido a partir dos esforços com a multimídia, ou seja, com os trabalhos que englobavam todo o espectro audiovisual, existente nos anos 80 do século XX, através de um programa de computador, a hipermídia associa à multimídia, o hipertexto. Desta associação, portanto, surge a possibilidade, até então inexistente na multimídia, qual seja da interação [...]

Hoje nossa relação com as narrativas se dá na convivência com a interatividade e a sincronicidade (por meio do uso dos computadores), com a possibilidade de colaboração entre diferentes leitores. Na web temos, ao mesmo tempo, multimídia, hipertexto e interatividade: hipermídia.

\section{ECOSSISTEMA COMUNICATIVO: A DEMANDA DE UM NOVO PARADIGMA PARA A EDUCAÇÃO}

O impacto disso ultrapassa, claro, o campo das publicações em formato livro: outras indústrias até então consolidadas (como a da música, a do cinema e a da informação) vêm passando também por profundas transformações. Diante da profusão de linguagens que hoje se misturam ao cotidiano de todos, incluindo crianças e jovens, a escola tem sido pressionada entre as missões de transmitir a tradição (analógica e marcadamente verbal e estática) e de preparar nossas crianças e jovens para o futuro (digital-eletrônico, hipermidiático e interativo).

Vivemos imersos no que Martín-Barbero ${ }^{5}$ chamou de ecossistema comunicativo, que envolve e transforma, em especial, aqueles que estão construindo uma primeira percepção de mundo: "Trata-se de uma experiência cultural nova ou, como chamou Walter Benjamin, um sensorium novo. Novos modos de perceber e sentir; uma nova sensibilidade [...]".

Cabe a nós, pesquisadores, investigar as oportunidades e seus impactos, rejeitando a resistência natural que se impõe ao novo, e cabe ao educomunicador perceber as oportunidades que podem surgir das interposições entre mídia, tecnologia, cultura e educação, conforme recomenda Maria Cristina Castilho Costa ${ }^{6}$ :

4. PETRY, Arlete. Análise de produções em linguagem hipermidiática. In TORRES, Rui; BAIRON, Sérgio (orgs). Conhecimento e (m) Hipermídia. Revista Cibertextualidades. Porto: Universidade Fernando Pessoa, 2009, n. 3, p. 142-143.

5. MARTÍN-BARBERO, Jesús. Desafios culturais: da comunicação à educomunicação. In $\mathrm{Cl}$ TELLI, Adílson; COSTA, Maria Cristina Castilho (orgs). Educomunicação - Construindo uma nova área de conhecimento. São Paulo: Paulinas, 2011, p. 125.

6. COSTA, Maria Cristina Castilho. Educação, imagens e mídia. São Paulo. Cortez, 2005, p. 21. 
É nesse cenário que a educação tem que rever seu paradigma letrado e adentrar o campo das imagens e das linguagens tecnológicas para que possa ultrapassar as barreiras que separam duas culturas: uma eurocentrada, iluminista e burguesa, baseada na escrita como forma de produção e controle do conhecimento; e outra, globalizada, massiva, baseada em múltiplas linguagens e tecnologias de comunicação, dentre as quais se afirmam de forma hegemônica os meios audiovisuais. Essa superação de barreiras não é fácil nem imediata, é um trabalho que envolve debates, experimentação, análise e avaliação, em um processo com avanços e recuos, mas firme e definitivo.

Assim emerge a Educomunicação, como um paradigma que nos possibilita entender, planejar, realizar e gerenciar processos educativos inclusivos e envolventes que têm na comunicação (mediada ou não tecnologicamente) seu principal instrumento para a construção de um ecossistema que se sustenta pela construção coletiva do conhecimento e o desenvolvimento da autonomia dos indivíduos.

Ismar de Oliveira Soares, pioneiro na pesquisa acadêmica que deu origem a esse campo de pesquisa e atuação no Brasil, a partir da sua atuação no NCE (Núcleo de Comunicação e Educação), da ECA-USP (Escola de Comunicação de Artes da Universidade de São Paulo), descreve assim a Educomunicação:

[...] é o conjunto das ações inerentes ao planejamento, implementação e avaliação de processos comunicativos, assim como de programas e produtos com intencionalidade educativa, destinados a criar e fortalecer ecossistemas comunicativos abertos, criativos, sob a perspectiva da gestão compartilhada e democrática dos recursos da informação?.

É, pois, considerando esse paradigma - "compatível com todas as modalidades de educação: a formal (escolar, curricular), a não formal (popular, não sistemática) e a informal (midiática, esporádica)" ${ }^{8}$ - que nos propusemos a analisar, por meio de pesquisa bibliográfica e de campo, entrevistas em profundidade e o relato de um experimento, as principais preocupações e percepções dos profissionais envolvidos na cadeia de produção e difusão do livro (autores de diversas linguagens, editores, mediadores e pesquisadores) diante de um formato específico de livro, o livro-aplicativo: que possibilita de forma bastante rica a fusão dos discursos verbal, imagético, sonoro e de interação para narrar uma história em suporte tablet ou smartphone.

7. SOARES, Ismar de Oliveira. Teorias da Comunicação e Filosofias da Educação: fundamentos epistemológicos da Educomunicação. Texto para a aula do concurso de titular. ECA-USP, 2009, p. 161

8. Idem, ibidem, p. 162.

9. CITELLI, Adilson. Outras linguagens na escola. São Paulo: Cortez, 2000.

\section{LIVROS-APLICATIVOS: LEITURA É TAMBÉM COMUNICAÇÃO E EDUCAÇÃO}

A despeito de mudanças de suporte e de linguagem que suscitam dúvidas, os livros-aplicativos criam também novas possibilidades nos campos de criação e de mediação, desde que sejam despidos os preconceitos e as ilusões de salvação que acompanham todas as novidades tecnológicas (conforme Citelli ${ }^{9}$ ) e que sejam contornados os desafios naturais para a adoção de qualquer tecnologia. 
Livros-aplicativos, ou book apps, são uma especificidade dentro da categoria de livros digitais e suas diferenças estão tanto no formato como na organização da multilinguagem. São softwares executados por determinados aparelhos (tablets e smartphones) conforme sua programação específica. Cada livro-aplicativo dá ordens à máquina (o suporte em que é lido) conforme a interatividade com o usuário - e não necessita ser lido por um programa para ser, então, decifrado (o que o tornaria limitado).

Daí a capacidade dos livros-aplicativos de integrar à narrativa as possibilidades do suporte - por exemplo, o uso de microfone, câmeras, bússola, caixas de som e tela altamente sensível ao toque, além do possível acesso à internet e a outras aplicações - e oferecer uma fusão de discursos em diversas linguagens, conforme sugere $\operatorname{Gosciola}^{10}$ ao definir hipermídia: "permite acesso simultâneo a textos, imagens e sons de modo interativo e não linear, possibilitando fazer links entre elementos de mídia, controlar a própria navegação [...] cuja sequência constituirá uma versão pessoal [...]”.

A saber, outros formatos de livro digital que podem ser lidos em tablets, mas não foram foco da pesquisa que deu origem a este artigo, são os PDFs arquivos que não permitem a fusão das linguagens ou uso de recursos audiovisuais - ; e os ePubs e os Mobi, formatos bastante universais, mas que excluem uma série de recursos de design (justamente por razões de universalização).

Da evolução dos ePubs, surgiram os enhanced eBooks ou e-Books interativos, que usam linguagem de programação HTML5, resultando no que é conhecido como ePub3 ou em ePubs de layout-fixo. Neles, alguns elementos audiovisuais e interatividades simples podem ser inseridos nas narrativas, mas não há relação de sincronicidade entre esses discursos. Por não serem softwares, esses arquivos não podem lançar mão de possibilidades do suporte para oferecer a mesma complexidade hipermidiática (e profundidade de experiência) de um livro-aplicativo ou book app, conforme exemplifica Carissa Kluver ${ }^{11}$.

Entender as motivações e desafios de criação de narrativas que abarquem novas linguagens para publicação em tablets no formato book app é um primeiro passo, sistematizador, para que a comunicação entre os criadores e publicadores garanta a riqueza de linguagens e, ao mesmo tempo, sua clareza e harmonia - o que é essencial para engajar leitores e promover experiências novas e profundas com a leitura.

Por outro lado, conhecer dificuldades e possibilidades geradas na apreensão que se faz de livros-aplicativos permitirá a educadores pensar uma mediação que contemple a literacia e a crítica dessas novas mídias, a imersão nessa experiência com a arte e ainda o protagonismo na criação de um ecossistema comunicativo profícuo.
10. GOSCIOLA, Vicente. Roteiro para as novas mídias: Do game à TV interativa. São Paulo: Senac, 2003, p. 34.

11. KLUVER, Carissa. Blurring the Digital Page: The Difference Between Book Apps and eBooks. Disponível em: $<$ http://digitalmediadiet. $\mathrm{com} / ? \mathrm{p}=2913>$. Acesso em: 5 abr. 2015. 


\section{METODOLOGIA}

Para reunir os desafios e as oportunidades que movem criadores, produtores, pesquisadores e mediadores de livros-aplicativos no Brasil, foram empreendidas doze entrevistas e ainda executada e analisada uma atividade de mediação de livros-aplicativos com estudantes de seis a oito anos na Escola Estadual Brasílio Machado, em São Paulo.

Dentre os entrevistados estão os autores e ilustradores Angela-Lago, Marcelo D’Salete (também educador), Ricardo Azevedo, Roberta Asse e Susana Ventura (também pesquisadora); as pesquisadoras Marisa Midore Daecto e Nelly Novaes Coelho; os profissionais do campo da edição de livros Antonio Henrique Santos, Idenize Alves, Lilian Scutti e Marília Mendes; e a mediadora Maria Claudia Brigido.

A pesquisa foi realizada no ano de 2015 como parte conclusiva de uma especialização em Educomunicação $\left(\mathrm{PINTO}^{12}\right)$ e reuniu a experiência prática da pesquisadora - cofundadora de uma publicadora de livros-aplicativos - à de outros profissionais e especialistas do livro e da educação, que remontaram suas experiências (de sucesso ou não) com publicações digitais interativas nos primórdios do uso desse formato eletrônico e hipermidiático e, em especial, num momento em que o formato apenas começa a ser experimentado no Brasil.

A abordagem educomunicativa aparece nesse estudo tanto quando se analisa a adoção dos tablets e dos livros-aplicativos na contação de histórias para crianças e jovens - o que é apontado também como uma atividade educativa e formativa da linguagem e da personalidade de cada indivíduo - quanto nos momentos em que se discute sobre o próprio processo de criação e produção desses livros, considerando a Educomunicação também como um processo de gestão da comunicação da equipe, de modo a garantir um ecossistema comunicativo bastante funcional para que o resultado, embora polifônico, seja equilibrado e harmônico.

12. PINTO, Samira Almeida. Literatura infantil e juvenil em hipermídia: da produção editorial à prática educomunicativa com livros-aplicativos. Monografia de especialização em Educomunicação na Escola de Comunicação e Artes na Universidade de São Paulo. São Paulo: 2015.

\section{DESAFIOS, OPORTUNIDADES E CRÍTICAS}

Optamos por reunir os principais desafios e as oportunidades percebidas por quem tem atuado com livros diante da emergência desse novo formato, além das críticas aos livros-aplicativos em pequenos apontamentos que, portanto, não trazem análises mais profundas, nem as citações dos entrevistados em si. Recomendamos a leitura da pesquisa original - em especial das entrevistas de seu anexo - para encontrar debates mais aprofundados e ainda pontos que, por não serem o foco da pesquisa, foram deixados de lado, embora apareçam com relevância nas falas dos entrevistados. 


\subsection{Principais críticas ao formato livro-aplicativo}

As principais críticas ouvidas na pesquisa estão ligadas justamente ao pouco tempo de que dispomos da tecnologia para criação, publicação e leitura de histórias - ainda é cedo para se ter certezas dos seus impactos, então dois dos entrevistados disseram que, ao misturar linguagens demais (especialmente quando se fala de incluir filmes e jogos na narrativa), tira o caráter imaginativo da atividade de leitura, dificultando o diálogo entre autor e leitor através da obra.

Apesar do aparente desejo de manter a leitura como uma atividade que prioriza a linguagem verbal sobre as outras, seis dos entrevistados mostraram julgar que os book apps são mais experimentais e inovadores à medida que são pensados e desenvolvidos por profissionais com formação e experiência de fora da cadeia do livro. Para eles, o desejo de tornar esta criação num produto vendável rapidamente tem sido um entrave para verdadeiras inovações de formato.

Prova de que é um ponto ainda bastante discutido por todos os agentes da cadeia de produção e difusão do livro, a CBL — Câmara Brasileira do Livro - criou, em 2015 e em caráter experimental, a categoria "Infantil Digital" do Prêmio Jabuti (maior distinção da literatura no país). Na primeira premiação as regras foram bastante adequadas ao formato de livros-aplicativos (dois dos aplicativos apresentados na pesquisa foram vencedores, um publicado pela autora deste artigo) e isso gerou muito debate entre as editoras nacionais de livros convencionais, que pediram modificações nas exigências para a próxima edição.

Por fim, outros dois entrevistados observaram que ainda há mais interesse das escolas em comprar os aparelhos do que em selecionar conteúdos e aplicativos para serem usados, bem como planejar as aulas para isso, o que revela uma visão de consumo destes aparelhos e serviços que se sobrepõe ao seu uso consciente e à ressignificação dos objetivos das atividades.

\subsection{Principais oportunidades percebidas no formato livro-aplicativo}

Oito dos doze entrevistados alegaram ser evidente que, diante de uma narrativa apresentada em suporte tablet e com linguagens e interações complementares, o leitor fica mais curioso e engajado, pois esses aparelhos e seus conteúdos estão ligados à ideia de diversão e acesso à cultura pop e possibilitam, dentro de espaços educativos, uma atividade que se assemelha muito à sua rotina extra-escolar.

Nessa questão, apareceram inclusive comentários que indicavam que esse envolvimento novo com a leitura pode ser usado como uma oportunidade para que se resgatem narrativas tradicionais e clássicas importantes para os novos leitores.

Um terço dos profissionais ouvidos percebe nos livros-aplicativos uma maneira de apresentar e equilibrar diferentes linguagens de comunicação, uma 
necessidade pungente diante de uma atualidade em que interpretar com profundidade imagens e sons é tão importante quanto fazer o mesmo com textos.

Do mesmo modo, a ampliação da experiência de leitura que pode ser feita a partir de livros-aplicativos (narrativas que se desdobram em diferentes formatos) é bem-vista, especialmente quando a interatividade pode alterar a narrativa ou quando ela relaciona o conteúdo da leitura a elementos exteriores que fazem parte da rotina da criança ou do jovem (com uso de câmeras, gravações etc). Nesse sentido, ao oferecer ao leitor a possibilidade de exercitar emoções conforme interage com a história narrada e seus personagens é uma forma de estimular o protagonismo, reforçar a autoestima e treinar habilidades comunicativas e criativas.

A mediação de leitura também é apontada como uma atividade beneficiada pelo novo formato - justamente porque ganha uma série de novas estratégias para recontar uma história, promover atividades educativas e recreativas.

Por fim, a acessibilidade para todo tipo de leitor (incluindo não letrados ou com outras dificuldades) aparece como um forte componente da leitura em aplicativos que unem linguagens e interatividades bem planejadas.

\subsection{Principais desafios para os livros-aplicativos no Brasil atualmente}

A criação de livros-aplicativos está ainda numa fase bastante inicial no Brasil e as razões encontradas nesta pesquisa não são difíceis de observar: existe, como ocorre diante de toda nova tecnologia e linguagem, uma dificuldade de domínio estrutural (das linguagens em si). Como o trabalho de qualquer autor se dá justamente sobre as possibilidades da linguagem que utiliza, no caso sua capacidade criativa fica bastante abalada e ele passa a depender mais da colaboração de outros especialistas.

Eis, então, o segundo grande desafio: se antes um autor trabalhava sozinho em sua obra, hoje as equipes são bem maiores e a negociação é uma das principais atividades no processo de criação.

Outra consequência disso é o alto custo da produção. Além de haver muitos especialistas a serem recompensados num só projeto, por uma cisão de mercado existem hoje duas tecnologias proprietárias (iOS e Android) que acabam dobrando a quantidade de trabalho a ser feito. No lado oposto ao investimento necessário, uma dúvida preocupa os editores convencionais: como comunicar e vender um produto tão diferente?

Somam-se a isto a ambivalência do governo brasileiro (maior comprador de livros do país), o pouquíssimo incentivo governamental à inovação nessa área e a lentidão da penetração dos tablets como suporte de leitura no espaço escolar nacional (especialmente no ensino público), o que dificulta uma estratégia de criação e venda no modelo típico de trabalho das grandes editoras. 
Cinco entrevistados relataram dificuldades na aproximação com educadores, seja por resistência, problemas estruturais e financeiros nas escolas, ou por falta de treinamento e habilidade com o suporte. Isso não foi confirmado na atividade relatada na pesquisa, quando identificamos professores interessados nos tablets e nos livros-aplicativos.

Por fim, a maneira como as lojas em que se vendem livros-aplicativos se organizam não beneficia esse tipo de negócio, expondo-o nas mesmas estantes que outros aplicativos e, inclusive, jogos - o que afeta sua precificação para baixo e dificulta o descobrimento de bons book apps.

\section{COMPETÊNCIAS EDUCOMUNICATIVAS}

Diante do panorama traçado, é possível perceber demandas prementes da atuação do profissional de Educomunicação tanto na área de produção como na de difusão do livro-aplicativo.

Considerando que o educomunicador deve trabalhar para que o resultado de sua ação seja o fortalecimento da comunicação em diferentes ecossistemas, observam-se oportunidades para sua atuação tanto em ambientes de educação quanto no gerenciamento da relação entre criadores, publicadores e mediadores desses book apps - permitindo que surjam produtos e políticas mais adequados aos desejos e necessidades dos leitores, que os levem para novas experiências expressivas.

Se o gerenciamento do processo produtivo dessas novas narrativas é apresentado por vários entrevistados como um desafio de atualização profissional para o editor, incluir a Educomunicação na sua formação é uma forma de possibilitar que os mais diferentes criativos tenham sua voz refletida na produção e que, assim, as linguagens tenham suas múltiplas possibilidades exploradas em profundidade - o que deve resultar em mais experimentos e inovações.

Já no campo da Educação em si, apresentam-se oportunidades de ação mais semelhantes àquelas que já estão associadas à Educomunicação. Uma delas é a capacitação de educadores, que deve incluir, além de quesitos técnicos de uso dos equipamentos, um viés reflexivo, analítico e comunicativo forte. Martín-Barbero ${ }^{13}$ aponta que "diante do professor que sabe recitar muito bem sua lição, hoje, senta-se um alunado que, por osmose com o meio ambiente comunicativo, está embebido em outras linguagens, saberes e escrituras que circulam pela sociedade". Por isso é importante não apenas instrumentalizar o educador, mas oferecer também espaço para a reflexão que deve prepará-lo, inclusive emocionalmente, para lidar com um ambiente diferente de ensino e aprendizagem e ainda, torná-lo apto a avaliar em diversos níveis os conteúdos que podem ser usados nas mais diversas situações de aprendizado.

Da mesma forma, o educomunicador pode colaborar imensamente com o ambiente educativo ao assumir o planejamento e a facilitação do uso das diversas tecnologias, minimizando desafios técnicos e estruturais ainda durante
13. MARTÍN-BARBERO, Jesús. Desafios culturais: Da comunicação à educomunicação. In: CITELLI, Adílson; COSTA, Maria Cristina Castilho (orgs). Educomunicação - Construindo uma nova área de conhecimento. São Paulo: Paulinas, 2011, p. 126. 
o planejamento das atividades. Esse profissional evitaria não apenas as dificuldades em si, mas também seria um ótimo agente contra o preconceito e a insegurança de educadores que, diante de problemas estruturais, tendem a simplesmente evitar o que pode gerar imprevistos em sua rotina.

Se um dos desafios está em fazer conversar os criativos, os empreendedores e a escola (os educadores), quem mais habilitado para criar essa interface do que um profissional cuja formação é focada em entender os fenômenos entrefronteiras de comunicação e educação para facilitar o acesso à informação, experimentação e troca de opiniões e experiências?

Por fim, os profissionais com formação nessa área tendem a ser ótimos mediadores para livros-aplicativos - justamente por seu conhecimento nos campos de educação (aqui incluem-se todas as interfaces que relacionam a área ao campo das narrativas) e tecnologia. Podem ainda criar, em suas atividades, a transição de um tipo de leitura para outro - fazer leituras comparativas de narrativas semelhantes em diferentes linguagens - de modo a ampliar o conceito e a experiência de leitura e possibilitar que se desenvolva o senso crítico de crianças, jovens, educadores e pais na escolha de que tipo de produtos e suportes de leitura os agrada mais.

Converter a comunicação "na vértebra dos processos educativos: educar pela comunicação e não para a comunicação" (conforme Soares ${ }^{14}$ ) é a missão da Educomunicação e, por isso, o campo das inovações em leitura para crianças e jovens pode ser um atraente ambiente de atuação, onde o educomunicador poderá pensar, gerir e difundir uma cultura de inclusão e um processo educativo que revalorize e transmita o passado para crianças e jovens de hoje, ao passo que os prepara para escrever em sua própria linguagem e com suas próprias práticas e reflexões, um futuro de múltiplas oportunidades.

14. SOARES, Ismar de Oliveira. Educomunicação: Um campo de mediações. In: CITELLI, Adílson; COSTA, Maria Cristina Castilho (orgs.). Educomunicação - Construindo uma nova área de conhecimento. São Paulo: Paulinas, 2011, p. 23.

\section{REFERÊNCIAS}

CALVINO, Ítalo. Fábulas italianas. São Paulo: Companhia das Letras, 1993.

CITELLI, Adilson. Outras linguagens na escola. São Paulo: Cortez, 2000.

COSTA, Maria Cristina Castilho. Educação, imagens e mídia. São Paulo: Cortez, 2005.

COSTA, Maria Cristina Castilho. A milésima segunda noite: Da narrativa mítica à telenovela — Análise estética e sociológica. São Paulo: Annablume/ Fapesp, 2000.

ECO, Umberto. Seis passeios pelos bosques da ficção. São Paulo: Companhia das Letras, 1994.

GOSCIOLA, Vicente. Roteiro para as novas mídias: Do game à TV interativa. São Paulo: Senac, 2003. 
KLUVER, Carissa. Blurring the Digital Page: The Difference Between Book Apps and eBooks. Disponível em: <http://digitalmediadiet.com/?p=2913>. Acesso em: 5 abr. 2015.

MARTÍN-BARBERO, Jesús. Desafios culturais: Da comunicação à educomunicação. In: CITELLI, Adílson; COSTA, Maria Cristina Castilho (orgs). Educomunicação - Construindo uma nova área de conhecimento. São Paulo: Paulinas, 2011.

PETRY, Arlete. Análise de produções em linguagem hipermidiática. In: TORRES, Rui; BAIRON, Sérgio (orgs). Conhecimento e(m) Hipermídia. Revista Cibertextualidades . Porto: Universidade Fernando Pessoa, 2009, n. 3.

PINTO, Samira Almeida. Literatura infantil e juvenil em hipermídia: da produção editorial à prática educomunicativa com livros-aplicativos. Monografia de especialização em Educomunicação na Escola de Comunicação e Artes na Universidade de São Paulo. São Paulo: 2015.

SOARES, Ismar de Oliveira. Teorias da Comunicação e Filosofias da Educação: Fundamentos epistemológicos da Educomunicação. Texto para a aula do concurso de titular. ECA-USP, 2009.

Educomunicação: Um campo de mediações. In:

CITELLI, Adílson; COSTA, Maria Cristina Castilho (orgs.). Educomunicação — Construindo uma nova área de conhecimento. São Paulo: Paulinas, 2011. 